\title{
Systemic inflammation is associated with the density of immune cells in the tumor microenvironment of gastric cancer
}

\author{
Yeonjoo Choi ${ }^{1} \cdot$ Jin Won $\mathrm{Kim}^{1}{ }^{(\mathbb{D}} \cdot \mathrm{Kyung}_{\mathrm{Han}} \mathrm{Nam}^{2} \cdot$ Song-Hee $\mathrm{Han}^{3}$. \\ Ji-Won Kim ${ }^{1} \cdot$ Sang-Hoon Ahn $^{4} \cdot$ Do Joong Park ${ }^{4} \cdot$ Keun-Wook Lee ${ }^{1}$. \\ Hye Seung Lee ${ }^{3}$ Hyung-Ho Kim ${ }^{4}$
}

Received: 30 May 2016/Accepted: 5 September 2016/Published online: 24 September 2016

(c) The International Gastric Cancer Association and The Japanese Gastric Cancer Association 2016

\begin{abstract}
Background The neutrophil-lymphocyte ratio (NLR) and the prognostic nutritional index (PNI) are markers of systemic inflammation known to be useful prognostic indicators of malignancy. However, little evidence has defined the influence of inflammation on the tumor microenvironment.

Methods Two hundred eighty-eight patients who underwent curative surgery for gastric cancer were included. Preoperative peripheral blood samples were used to analyze the NLR and PNI. The optimal cutoff levels for the NLR and PNI were defined by receiver operating characteristic curve analysis for survival $(\mathrm{NLR}=2.7$, PNI $=47.7)$. The densities of specific immune cells $\left(\mathrm{CD}^{+}, \mathrm{CD}^{+}, \mathrm{CD}^{+}\right)$within the tumor microenvironment were measured in tumor microarrays by immunohistochemical analysis.
\end{abstract}

Jin Won Kim

jwkim@snubh.org

1 Division of Hematology and Medical Oncology, Department of Internal Medicine, Seoul National University Bundang Hospital, Seoul National University College of Medicine, 82 Gumi-ro, Bundang-gu, Seongnam-si, Gyeonggi-do 13620, Republic of Korea

2 Department of Pathology, Haeundae Paik Hospital, Inje University College of Medicine, 875, Haeun-daero, Haeundae-gu, Busan 48108, Republic of Korea

3 Department of Pathology, Seoul National University Bundang Hospital, Seoul National University College of Medicine, 82 Gumi-ro, Bundang-gu, Seongnam-si, Gyeonggi-do 13620, Republic of Korea

4 Department of Surgery, Seoul National University Bundang Hospital, Seoul National University College of Medicine, 82 Gumi-ro, Bundang-gu, Seongnam-si, Gyeonggi-do 13620, Republic of Korea
Results Two hundred thirty-five patients $(81.6 \%)$ had a low NLR and 53 patients $(18.4 \%)$ had a high NLR. One hundred seventeen patients $(40.6 \%)$ had a low PNI and 171 patients $(59.4 \%)$ had a high $\mathrm{PNI} . \mathrm{CD}^{+}$and $\mathrm{CD} 8^{+}$ immune cell density were not associated with the NLR and PNI. However, in the high-NLR group compared with the low-NLR group, $\mathrm{CD}^{+}{ }^{+}$immune cell density was significantly decreased $(P<0.001)$. Similarly, the density of $\mathrm{CD} 4{ }^{+}$immune cells was also significantly decreased in the low-PNI group compared with the high-PNI group $(P=0.007)$. A high NLR and a low PNI were correlated with worse overall survival in multivariate analysis ( $P=0.028$ and $P=0.002$ respectively).

Conclusions The NLR and PNI are associated with the density of $\mathrm{CD}^{+}{ }^{+}$immune cells in the tumor microenvironment, which leads to prognostic values of systemic inflammation in gastric cancer.

Keywords Neutrophil-lymphocyte ratio - Prognostic nutritional index $\cdot$ Immune cell . Tumor microenvironment $\cdot$ Gastric cancer

\section{Introduction}

Tumor inflammatory response has been shown to play an important role in cancer development and progression, and inflammatory cells are regarded as essential components of the tumor microenvironment [1]. Several studies have demonstrated that tumor-infiltrating lymphocytes are present in the tumor microenvironment in various malignant tumors [2-4]. The presence of tumor-infiltrating lymphocytes is correlated with a better prognosis in several types of cancer, and different subsets of T lymphocytes appear to play unique roles in the antitumor response [5-9]. 
Recently, the presence of tumor-infiltrating lymphocytes was reported as a predictive biomarker of the response to trastuzumab and anthracycline plus taxane in breast cancer [10-12]. These data suggest that the presence of inflammatory cells in the tumor microenvironment could play a valuable predictive role for response to cancer immunotherapy [13, 14].

Systemic inflammation is also correlated with cancer prognosis. Many lines of evidence indicate that markers of systemic inflammation are independent prognostic factors for survival in many malignancies, including colon cancer, lung cancer, pancreatic cancer, hepatobiliary cancer, and gastric cancer [1,15-22]. The neutrophil-lymphocyte ratio (NLR) is one such commonly used marker that has been reported as a prognostic factor [20-22]. The NLR is calculated on the basis of the presence of cell types known to be regulated by cytokines, particularly interleukin-6 [23]. Like the NLR, albumin levels, lymphocyte count, thrombocytosis, and the prognostic nutritional index (PNI) are also correlated with prognosis and survival rate in many solid cancers $[17,18]$. Albumin, which is associated with chronic inflammation reactions, may also be a marker of cancer inflammation [19]. Interleukin-6 stimulates hepatocytes to induce expression of acute-phase proteins, including C-reactive protein, and decrease serum albumin levels [23]. The poor prognosis associated with systemic inflammation could be explained by a role in the tumor microenvironment in which cytokines or immune cells present because of systemic inflammation promote tumor progression [16]. Data are needed to support this hypothesis, as little evidence currently exists. Prediction of the immune response in the tumor microenvironment is very important for selection of patients who will most likely benefit from cancer immunotherapy. Currently, inflammation in the tumor microenvironment can be assessed only microscopically with biopsy samples. However, as many cytokines and other inflammatory cells are known to migrate from blood to local tissues via systemic circulation, markers of systemic inflammation could be used to predict cancer prognosis associated with immune responses in the tumor microenvironment [14, 24].

To address these questions, we evaluated the prognostic value of markers of systemic inflammation (the NLR and PNI) and investigated the association between systemic inflammation and the presence of immune cells in the tumor microenvironment.

\section{Patients and methods}

\section{Patients}

Two hundred eighty-eight patients underwent gastric resection between May 2003 and December 2004 at Seoul
National University Bundang Hospital. All patients received curative-intent resection with $\mathrm{D} 2$ lymph node dissection. Gastric adenocarcinoma was confirmed in all patients. On the basis of clinical information from electronic medical records, the median follow-up duration was 86.9 months (range $0-127$ months). We tried to identify the Helicobacter pylori infection from presurgical endoscopic records. For patients whose date of death could not be verified through electronic medical records, the date was obtained from records from the Ministry of Public Administration and Security in Korea. This study was approved by the Institutional Review Board of Seoul National University Bundang Hospital (B-1508/312-310).

\section{Markers of systemic inflammation}

Routine clinical laboratory analyses of peripheral blood samples collected within 2 weeks before the operation were used to ascertain neutrophil counts, lymphocyte counts, and albumin concentrations. Patients with preoperative sepsis or confirmed systemic infection were excluded. The NLR and PNI, which do not have overlapping parameters, were used as markers of systemic inflammation. As previously reported, the NLR was calculated as the ratio of the neutrophil count to the lymphocyte count [25]. The PNI was calculated as described previously: $10 \times$ albumin concentration $(\mathrm{g} / \mathrm{dL})+0.005 \times$ total lymphocyte count $\left(/ \mathrm{mm}^{3}\right)$ [26]. An optimal cutoff value was defined to classify the samples into two groups (high vs low) for each inflammation marker with use of the receiver operating characteristic curve for survival. The cutoff value for the NLR was defined to be 2.7 , with $27.9 \%$ sensitivity and $87.6 \%$ specificity [area under the curve $0.586,95 \%$ confidence interval 0.518-0.655], and the cutoff value for the PNI was defined to be 47.7 , with $57.7 \%$ sensitivity and $70.1 \%$ specificity (area under the curve $0.647,95 \%$ confidence interval 0.580-0.714).

\section{Quantification of the density of immune cells in the tumor microenvironment and cyclooxygenase 2}

Tissue microarrays were used for analysis of the tumor microenvironment, and were generated as follows. Tissue samples from surgical specimens were fixed in $10 \%$ buffered formalin for $24-48 \mathrm{~h}$ and then embedded in paraffin. Representative cores ( $2 \mathrm{~mm}$ in diameter) were isolated from individual paraffin blocks and arranged in new tissue array blocks with use of a trephine apparatus (Superbiochips Laboratories, Seoul, Korea). The patients included in the study had tumors occupying more than $10 \%$ of the core area. Nonneoplastic gastric mucosa specimens were 
also incorporated into each of the array blocks, and the tissue array blocks contained up to 60 cores.

The densities of $\mathrm{CD}^{+}, \mathrm{CD}^{+}$, and $\mathrm{CD} 8^{+}$immune cells in the tumor microenvironment were assessed with a previously described image analysis system [27, 28]. Arrays were stained with the following primary antibodies: rabbit polyclonal anti-CD3 (1:100 dilution, Dako, Glostrup, Denmark); rabbit monoclonal anti-CD4, clone SP35 (undiluted, Ventana Medical Systems, Tucson, AZ, USA); and mouse monoclonal anti-CD8, clone C8/144B (undiluted, Dako, Carpinteria, CA, USA). Briefly, stained slides were scanned at a magnification of $\times 200$ with a ScanScope CS2 instrument (Aperio Technologies, Vista, CA, USA), and scanned images were analyzed by ImageScope (version 12.0.0.5039, Aperio Technologies). Positive cells were quantified in each tumor region (both epithelial and stromal compartments) and scored as negative, weak (1+), moderate $(2+)$, or strong $(3+)$. Immune cell density was defined as the number of positive cells $(2+$ or $3+$ ) per unit of tissue surface area (in square millimeters).

Cyclooxygenase 2 (COX-2) expression was evaluated with commercially available primary antibodies according to the manufacturer's instructions (rabbit monoclonal antibody, 1:100 dilution, Optiview polymer, Ventana, Spring Bioscience). Expression was assessed as intensity (negative expression 0 , weak expression 1, moderate expression 2, and strong expression 3) and scored as the percentage of positive cells. A modified histochemical score was calculated from the intensity multiplied by the percentage of positive cells, ranging from 0 to 300 . According to the mean histochemical score (98.3), COX-2 expression was classified into low or high expression.

\section{Statistical analysis}

Differences in clinical parameters by NLR and PNI status were assessed by a chi-squared test. Associations between markers of systemic inflammation and the densities of immune cells in the tumor microenvironment were evaluated by a $t$ test or Pearson correlation by calculation of correlation coefficients. Disease-free survival (DFS) was estimated on the basis of the time between the date of surgery and the date of disease recurrence or death from any cause without recurrence. Overall survival (OS) was calculated from the date of surgery to the last follow-up or date of death from any cause. The survival rate was calculated by the Kaplan-Meier method, and statistical analysis was performed with the log-rank test. Multivariate analysis of prognostic factors was conducted with Cox's proportional hazards model. $P$ values less than 0.05 were considered statistically significant. Statistical analysis was performed with SPSS $19.0 \mathrm{~K}$ for Windows (SPSS, Chicago, IL, USA).

\section{Results}

\section{Patient characteristics}

Two hundred eighty-eight patients were enrolled, $62.8 \%$ of whom were male (Table 1). The median age was 62 years (range 28-87 years). Patients aged 70 years or older made up $21.9 \%$ of the cohort. Most of the patients underwent subtotal gastrectomy $(78.1 \%)$. Most cancers were identified as intestinal type $(45.1 \%)$ or diffuse type $(46.9 \%)$ by the Lauren classification. Approximately half of the patients (146 patients, $50.7 \%$ ) exhibited lymphatic invasion. Vascular invasion and neural invasion were observed in 32 patients $(11.1 \%)$ and 103 patients $(35.8 \%)$ respectively. The mean numbers of involved and examined nodes were $4.67(0-48)$ and $38.52(8-101)$ respectively. No lymph node was involved in 143 patients $(49.7 \%)$. One hundred nine patients $(37.8 \%)$ had a lymph node ratio (ratio of the number of involved to examined lymph nodes) in the range from more than 0 to $0.3,26$ patients $(9.0 \%)$ had a lymph node ratio in the range from greater than 0.3 to 0.6 , and 10 patients $(3.55 \%)$ had a lymph node ratio of more than 0.6. The percentages of cancers by stage were as follows: $49.3 \%$ for stage I cancer, $15.6 \%$ for stage II cancer, $30.2 \%$ for stage III cancer, and $4.9 \%$ for stage IV cancer. One hundred nine patients $(37.8 \%)$ received postoperative chemotherapy. H. pylori infection was identified in 99 patients $(34.4 \%)$. COX-2 expression was low in 158 patients $(54.9 \%)$ and high in 128 patients $(44.4 \%)$.

\section{Associations between clinicopathologic findings and markers of systemic inflammation}

The median NLR was 2.1 (range 0.4-19.7). Using the defined cutoff value (2.7), we identified 235 patients $(81.6 \%)$ as having a low NLR and 53 patients $(18.4 \%)$ as having a high NLR. The median PNI was 48.6 (range 32.6-65.5). On the basis of the cutoff value for the PNI (47.7), 117 patients (40.6\%) had a low PNI and 177 patients $(59.4 \%)$ had a high PNI.

The NLR and PNI were not correlated with sex, tumor location, or histologic type by the WHO classification or the Lauren classification (Table 2). A low PNI was more frequent in patients older than 70 years $(P=0.015)$. A high NLR was frequent in patients with vascular invasion or neural invasion ( $P=0.047$ and $P=0.025$ respectively). A low PNI was associated with lymphatic invasion $(P=0.010)$, vascular invasion $(P=0.022)$, and neural invasion $(P<0.001)$. A high NLR and a low PNI were more frequently found in patients with a higher lymph node ratio $(P=0.035$ and $P=0.018$ respectively). Moreover, a high NLR and a low PNI were correlated with cancer of a more advanced stage $(P=0.040$ and $P<0.001$ respectively). 
Table 1 Baseline characteristics

\begin{tabular}{|c|c|c|}
\hline Variable & $\begin{array}{l}\text { No. of patients } \\
(N=288)\end{array}$ & $\begin{array}{l}\text { Percentage } \\
\text { of patients }\end{array}$ \\
\hline \multicolumn{3}{|l|}{ Sex } \\
\hline Male & 181 & 62.8 \\
\hline Female & 107 & 37.2 \\
\hline \multicolumn{3}{|l|}{ Age (years) ${ }^{\mathrm{a}}$} \\
\hline$<70$ & 225 & 78.1 \\
\hline$\geq 70$ & 63 & 21.9 \\
\hline \multicolumn{3}{|l|}{ Operation } \\
\hline Subtotal gastrectomy & 225 & 78.1 \\
\hline Total gastrectomy & 63 & 21.9 \\
\hline \multicolumn{3}{|l|}{ WHO classification } \\
\hline Well to moderately differentiated & 133 & 46.1 \\
\hline Poorly differentiated & 104 & 36.1 \\
\hline Signet ring cell & 40 & 13.9 \\
\hline Mucinous & 9 & 3.1 \\
\hline Unclassified & 2 & 0.7 \\
\hline \multicolumn{3}{|l|}{ Lauren classification } \\
\hline Intestinal & 130 & 45.1 \\
\hline Diffuse & 135 & 46.9 \\
\hline Mixed & 23 & 8.0 \\
\hline \multicolumn{3}{|l|}{ Lymphatic invasion } \\
\hline Absent & 142 & 49.3 \\
\hline Present & 146 & 50.7 \\
\hline \multicolumn{3}{|l|}{ Vascular invasion } \\
\hline Absent & 256 & 88.9 \\
\hline Present & 32 & 11.1 \\
\hline \multicolumn{3}{|l|}{ Neural invasion } \\
\hline Absent & 185 & 64.2 \\
\hline Present & 103 & 35.8 \\
\hline \multicolumn{3}{|c|}{ Lymph node ratio (involved/examined lymph nodes) } \\
\hline 0 & 143 & 49.7 \\
\hline$>0$ to $\leq 0.3$ & 109 & 37.8 \\
\hline$>0.3$ to $\leq 0.6$ & 26 & 9.0 \\
\hline$>0.6$ & 10 & 3.5 \\
\hline \multicolumn{3}{|l|}{ Stage $^{\mathrm{a}}$} \\
\hline I & 142 & 49.3 \\
\hline II & 45 & 15.6 \\
\hline III & 87 & 30.2 \\
\hline IV & 14 & 4.9 \\
\hline \multicolumn{3}{|l|}{ Postoperative chemotherapy } \\
\hline Yes & 109 & 37.8 \\
\hline No & 179 & 62.2 \\
\hline \multicolumn{3}{|l|}{ Helicobacter pylori infection } \\
\hline Negative & 111 & 38.5 \\
\hline Positive & 99 & 34.4 \\
\hline Unknown & 210 & 27.1 \\
\hline COX-2 expression & & \\
\hline
\end{tabular}

Table 1 continued

\begin{tabular}{llc}
\hline Variable & $\begin{array}{l}\text { No. of patients } \\
(N=288)\end{array}$ & $\begin{array}{l}\text { Percentage } \\
\text { of patients }\end{array}$ \\
\hline Low & 158 & 54.9 \\
High & 128 & 44.4 \\
Unknown & 2 & 0.7 \\
\hline
\end{tabular}

COX-2 cyclooxygenase 2

a Median 62 years, range 28-87 years

b Based on the seventh edition of the AJCC Cancer Staging Manual of the American Joint Committee on Cancer

H. pylori infection was correlated with a low NLR $(P=0.042)$. However, there was no correlation between $H$. pylori infection and the PNI $(P=0.507)$. In terms of COX-2 expression, there was no significance related to the NLR and PNI.

\section{Associations between markers of systemic inflammation and the densities of immune cells in the tumor microenvironment}

The mean densities of $\mathrm{CD}^{+}, \mathrm{CD}^{+}$, and $\mathrm{CD} 8^{+}$immune cells in the tumor microenvironment in patient samples were $861.9,506.5$, and $631.6 / \mathrm{mm}^{2}$ respectively. Although the difference was not significant, the mean densities of $\mathrm{CD}^{+}{ }^{+}$immune cells and $\mathrm{CD} 8^{+}$immune cells were slightly lower in the high-NLR group than in the low-NLR group $\left(\mathrm{CD}^{+}{ }^{+}\right.$immune cells, $681.8 / \mathrm{mm}^{2}$ vs $903.5 / \mathrm{mm}^{2}$, $P=0.057 ; \mathrm{CD}^{+}$immune cells, $408.0 / \mathrm{mm}^{2}$ vs $570.0 /$ $\mathrm{mm}^{2}, P=0.133$; Table 3). Scatter plots also did not identify a significant correlation between the NLR and $\mathrm{CD}^{+}$or $\mathrm{CD}^{+}{ }^{+}$immune cell densities (correlation coefficients -0.064 and -0.028 respectively, $P=0.302$ and $P=0.675$ respectively, Fig. 1a, c). However, the mean density of $\mathrm{CD}^{+}{ }^{+}$immune cells in the high-NLR group $\left(324.6 / \mathrm{mm}^{2}\right)$ was significantly lower than that in the lowNLR group $\left(546.5 / \mathrm{mm}^{2}\right)(P<0.001$, Table 3$)$. Consistent with this observation, a scatter plot of the NLR and CD4 $4^{+}$ immune cell density in the tumor microenvironment revealed a significant inverse correlation (correlation coefficient $-0.175, P=0.007$, Fig. $1 \mathrm{~b}$ ). With respect to the PNI, no significant correlation was observed with $\mathrm{CD}^{+}$or $\mathrm{CD}^{+}$immune cell densities in the tumor microenvironment (correlation coefficients -0.018 and -0.065 respectively, $P=0.770$ and $P=0.324$ respectively, Fig. 1d, f). However, the PNI was positively correlated with $\mathrm{CD}^{+}$immune cell density in the tumor microenvironment (correlation coefficient 0.201, $P=0.002$, Fig. 1e). The mean density of $\mathrm{CD} 4^{+}$immune 
Table 2 Associations between clinicopathologic variables and systemic inflammation markers in gastric cancer

\begin{tabular}{|c|c|c|c|c|c|c|}
\hline \multirow[t]{2}{*}{ Variables } & \multicolumn{2}{|l|}{ NLR } & \multirow[t]{2}{*}{$P^{\mathrm{a}}$} & \multicolumn{2}{|l|}{ PNI } & \multirow[t]{2}{*}{$P^{\mathrm{a}}$} \\
\hline & Low $(n=235)$ & $\operatorname{High}(n=53)$ & & Low $(n=117)$ & $\operatorname{High}(n=171)$ & \\
\hline Sex & & & 0.140 & & & 0.895 \\
\hline Male & $143(79.0 \%)$ & $38(21.0 \%)$ & & $73(40.3 \%)$ & $108(59.7 \%)$ & \\
\hline Female & $92(86.0 \%)$ & $15(14.0 \%)$ & & $44(41.1 \%)$ & $63(58.9 \%)$ & \\
\hline Age (years) & & & 0.827 & & & 0.015 \\
\hline$<70$ & $183(81.3 \%)$ & $42(18.7 \%)$ & & $83(36.9 \%)$ & $142(63.1 \%)$ & \\
\hline$\geq 70$ & $52(82.5 \%)$ & $11(17.5 \%)$ & & $34(54.0 \%)$ & $29(46.0 \%)$ & \\
\hline Tumor location & & & 0.652 & & & 0.153 \\
\hline Lower third & $109(79.6 \%)$ & $28(20.4 \%)$ & & $62(45.3 \%)$ & $75(54.7 \%)$ & \\
\hline Middle third & $85(85.0 \%)$ & $15(15.0 \%)$ & & $32(32.0 \%)$ & $68(68.0 \%)$ & \\
\hline Upper third & $36(81.8 \%)$ & $8(18.2 \%)$ & & $19(43.2 \%)$ & $25(56.8 \%)$ & \\
\hline Entire stomach & $5(71.4 \%)$ & $2(28.6 \%)$ & & $4(57.1 \%)$ & $3(42.9 \%)$ & \\
\hline WHO classification $^{\mathrm{b}}$ & & & 0.246 & & & 0.156 \\
\hline Well to moderately differentiated & $110(82.7 \%)$ & $23(17.3 \%)$ & & $48(36.9 \%)$ & $82(63.1 \%)$ & \\
\hline Poorly differentiated & $83(79.8 \%)$ & $21(20.2 \%)$ & & $50(48.5 \%)$ & $53(51.5 \%)$ & \\
\hline Signet ring cell & $35(87.5 \%)$ & $5(12.5 \%)$ & & $13(32.5 \%)$ & $27(67.5 \%)$ & \\
\hline Mucinous & $5(55.6)$ & $4(44.4 \%)$ & & $4(44.4 \%)$ & $5(55.6 \%)$ & \\
\hline Lauren classification & & & 0.939 & & & 0.578 \\
\hline Intestinal & $107(82.3 \%)$ & $23(17.7 \%)$ & & $49(37.7 \%)$ & $81(62.3 \%)$ & \\
\hline Diffuse & $109(80.7 \%)$ & $26(19.3 \%)$ & & $57(42.2 \%)$ & $78(57.8 \%)$ & \\
\hline Mixed & $19(82.6 \%)$ & $4(17.4 \%)$ & & $11(47.8 \%)$ & $12(52.2 \%)$ & \\
\hline Lymphatic invasion & & & 0.119 & & & 0.010 \\
\hline Absent & $121(85.2 \%)$ & $21(14.8 \%)$ & & $47(33.1 \%)$ & $95(66.9 \%)$ & \\
\hline Present & $114(78.1 \%)$ & $32(21.9 \%)$ & & $70(47.9 \%)$ & $76(52.1 \%)$ & \\
\hline Vascular invasion & & & 0.047 & & & 0.022 \\
\hline Absent & $213(83.2 \%)$ & $43(16.8 \%)$ & & $98(38.3 \%)$ & $158(61.7 \%)$ & \\
\hline Present & $22(68.8 \%)$ & $10(31.1 \%)$ & & $19(59.4 \%)$ & $13(40.6 \%)$ & \\
\hline Neural invasion & & & 0.025 & & & $<0.001$ \\
\hline Absent & $158(85.4 \%)$ & $27(14.6 \%)$ & & $60(32.4 \%)$ & $125(67.6 \%)$ & \\
\hline Present & $77(74.8 \%)$ & $26(25.2 \%)$ & & $57(55.3 \%)$ & $46(44.7 \%)$ & \\
\hline Lymph node ratio (involved/examined lymph nodes) & & & $0.035^{\mathrm{c}}$ & & & $0.018^{\mathrm{c}}$ \\
\hline 0 & $122(85.3 \%)$ & $21(14.7 \%)$ & & $52(36.4 \%)$ & $91(63.6 \%)$ & \\
\hline$>0$ to $\leq 0.3$ & $88(80.7 \%)$ & $21(19.3 \%)$ & & $43(39.4 \%)$ & $66(60.6 \%)$ & \\
\hline$>0.3$ to $\leq 0.6$ & $18(69.2 \%)$ & $8(30.8 \%)$ & & $16(61.5 \%)$ & $10(38.5 \%)$ & \\
\hline$>0.6$ & $7(70.0 \%)$ & $3(30.0 \%)$ & & $6(60.0 \%)$ & $4(40.0 \%)$ & \\
\hline Stage by AJCC7 & & & $0.004^{\mathrm{c}}$ & & & $<0.001^{\mathrm{c}}$ \\
\hline I & $125(88.0 \%)$ & $17(12.0 \%)$ & & $44(31.0 \%)$ & $98(69.0 \%)$ & \\
\hline II & $37(82.2 \%)$ & $8(17.8 \%)$ & & $19(42.2 \%)$ & $26(57.8 \%)$ & \\
\hline III & $62(71.3 \%)$ & $25(28.7 \%)$ & & $37(51.7 \%)$ & $26(48.3 \%)$ & \\
\hline IV & $11(78.6 \%)$ & $3(21.4 \%)$ & & $9(64.3 \%)$ & $5(35.7 \%)$ & \\
\hline Helicobacter pylori infection & & & 0.042 & & & 0.507 \\
\hline Negative & $90(81.1 \%)$ & $21(18.9 \%)$ & & $41(36.9 \%)$ & $70(63.1 \%)$ & \\
\hline Positive & $90(90.9 \%)$ & $9(9.1 \%)$ & & $41(41.4 \%)$ & $58(58.6 \%)$ & \\
\hline COX-2 expression & & & 0.315 & & & 0.539 \\
\hline Low & $132(83.5 \%)$ & $26(16.5 \%)$ & & $61(38.6 \%)$ & $97(61.4 \%)$ & \\
\hline High & $101(78.9 \%)$ & $27(21.1 \%)$ & & $54(42.2 \%)$ & $74(57.8 \%)$ & \\
\hline
\end{tabular}

AJCC7 seventh edition of the AJCC Cancer Staging Manual of the American Joint Committee on Cancer, COX-2 cyclooxygenase 2, NLR neutrophil-lymphocyte ratio, $P N I$ prognostic nutritional index

${ }^{a}$ Performed by a chi-squared test

b Two missing data points were excluded

${ }^{c}$ Performed by linear by linear association 
Table 3 Associations between inflammation markers and immune cell density in the tumor microenvironment

\begin{tabular}{|c|c|c|c|}
\hline Variables & $\begin{array}{l}\text { Mean } \mathrm{CD}^{+} \text {immune } \\
\text { cell density }\left(/ \mathrm{mm}^{2}\right)\end{array}$ & $\begin{array}{l}\text { Mean } \mathrm{CD}^{+} \text {immune } \\
\text { cell density }\left(/ \mathrm{mm}^{2}\right)\end{array}$ & $\begin{array}{l}\text { Mean } \mathrm{CD}^{+} \text {immune } \\
\text { cell density }\left(/ \mathrm{mm}^{2}\right)\end{array}$ \\
\hline NLR & $P=0.057$ & $P<0.001$ & $P=0.133$ \\
\hline Low & 903.5 & 546.5 & 570.0 \\
\hline High & 681.8 & 324.6 & 408.0 \\
\hline $\begin{array}{l}\text { Difference between the } 2 \\
\text { groups }\end{array}$ & $221.7(95 \% \mathrm{CI}-7.1$ to 450.4$)$ & $221.8(95 \%$ CI 120.7-322.9) & $161.9(95 \% \mathrm{CI}-49.6$ to 373.4$)$ \\
\hline PNI & $P=0.376$ & $P=0.007$ & $P=0.173$ \\
\hline Low & 912.8 & 429.1 & 614.0 \\
\hline High & 826.0 & 559.8 & 490.3 \\
\hline $\begin{array}{l}\text { Difference between the } 2 \\
\text { groups }\end{array}$ & $286.9(95 \% \mathrm{CI}-106.5$ to 280.2$)$ & $-130.7(95 \% \mathrm{CI}-226.1$ to -35.3$)$ & $123.6(95 \% \mathrm{CI}-54.7$ to 302.0$)$ \\
\hline Helicobacter pylori infection & $P=0.742$ & $P=0.935$ & $P=0.613$ \\
\hline Negative & 861.1 & 516.1 & 496.7 \\
\hline Positive & 826.8 & 520.6 & 541.9 \\
\hline Difference between the 2 groups & $34.3(95 \% \mathrm{CI}-171.0$ to 239.6$)$ & $-4.5(95 \% \mathrm{CI}-113.5$ to 104.4$)$ & $-45.2(95 \% \mathrm{CI}-221.6$ to 131.2$)$ \\
\hline COX-2 expression & $P=0.314$ & $P=0.033$ & $P=0.571$ \\
\hline Low & 890.2 & 553.5 & 563.6 \\
\hline High & 800.3 & 452.1 & 516.1 \\
\hline Difference between the 2 groups & $89.9(95 \% \mathrm{CI}-85.5$ to 265.3$)$ & 101.4 (95 \% CI 8.3-194.4) & $47.5(95 \% \mathrm{CI}-117.3$ to 212.3$)$ \\
\hline
\end{tabular}

$C I$ confidence interval, $C O X-2$ cyclooxygenase 2, NLR neutrophil-lymphocyte ratio, PNI prognostic nutritional index

$\mathbf{a}$
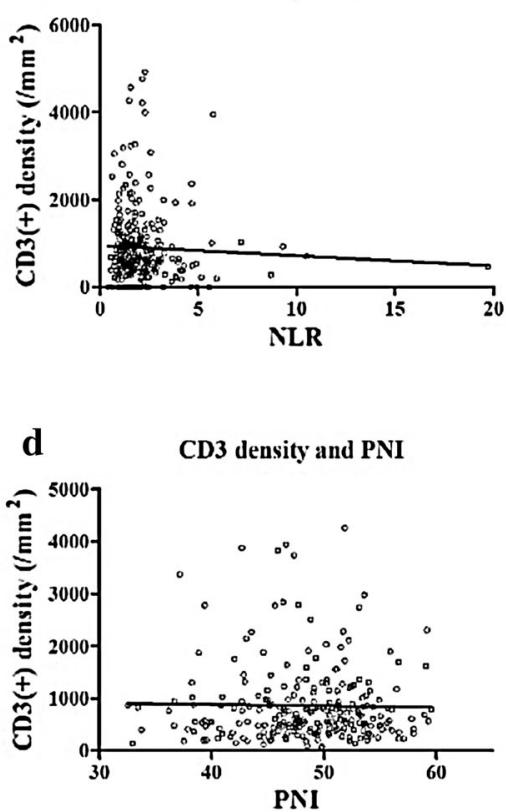

b

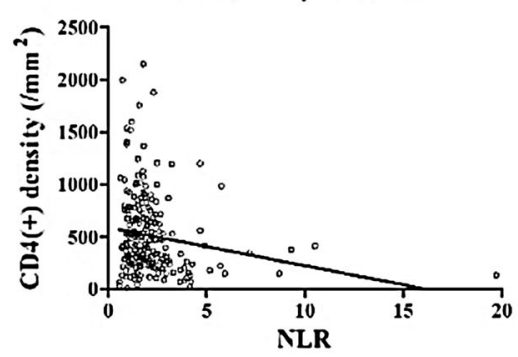

e

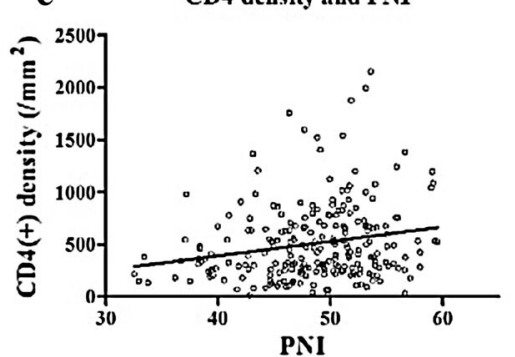

C
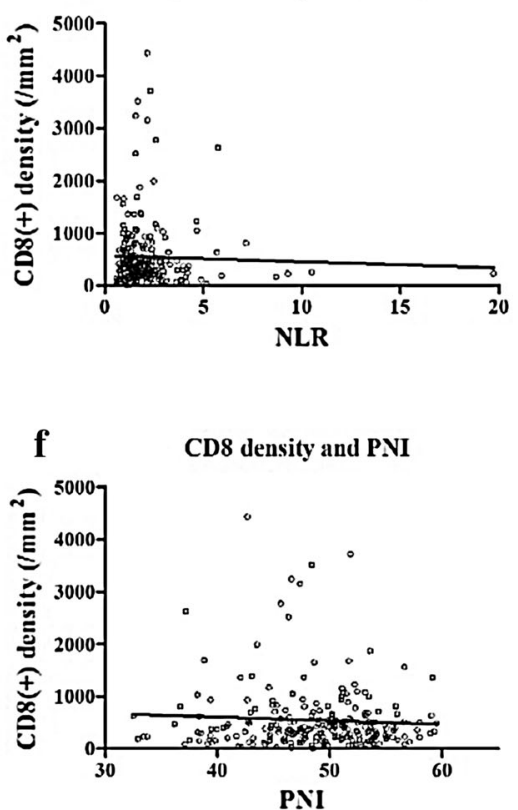

Fig. 1 Correlations between systemic inflammation markers and density of immune cells in the tumor microenvironment. NLR neutrophillymphocyte ratio, PNI prognostic nutritional index

cells in the low-PNI group $\left(429.1 / \mathrm{mm}^{2}\right)$ was lower than that in the high-PNI group $\left(559.8 / \mathrm{mm}^{2}\right)$.

Additionally, in terms of $H$. pylori infection, the densities of $\mathrm{CD}^{+}, \mathrm{CD}^{+}$, and $\mathrm{CD}^{+}$immune cells in the tumor microenvironment were not different $(P=0.742$, $P=0.935$, and $P=0.613$ respectively). There was no correlation of COX-2 expression to the densities of $\mathrm{CD}^{+}$ and $\mathrm{CD}^{+}$immune cells $(P=0.314$ and $P=0.571$ 

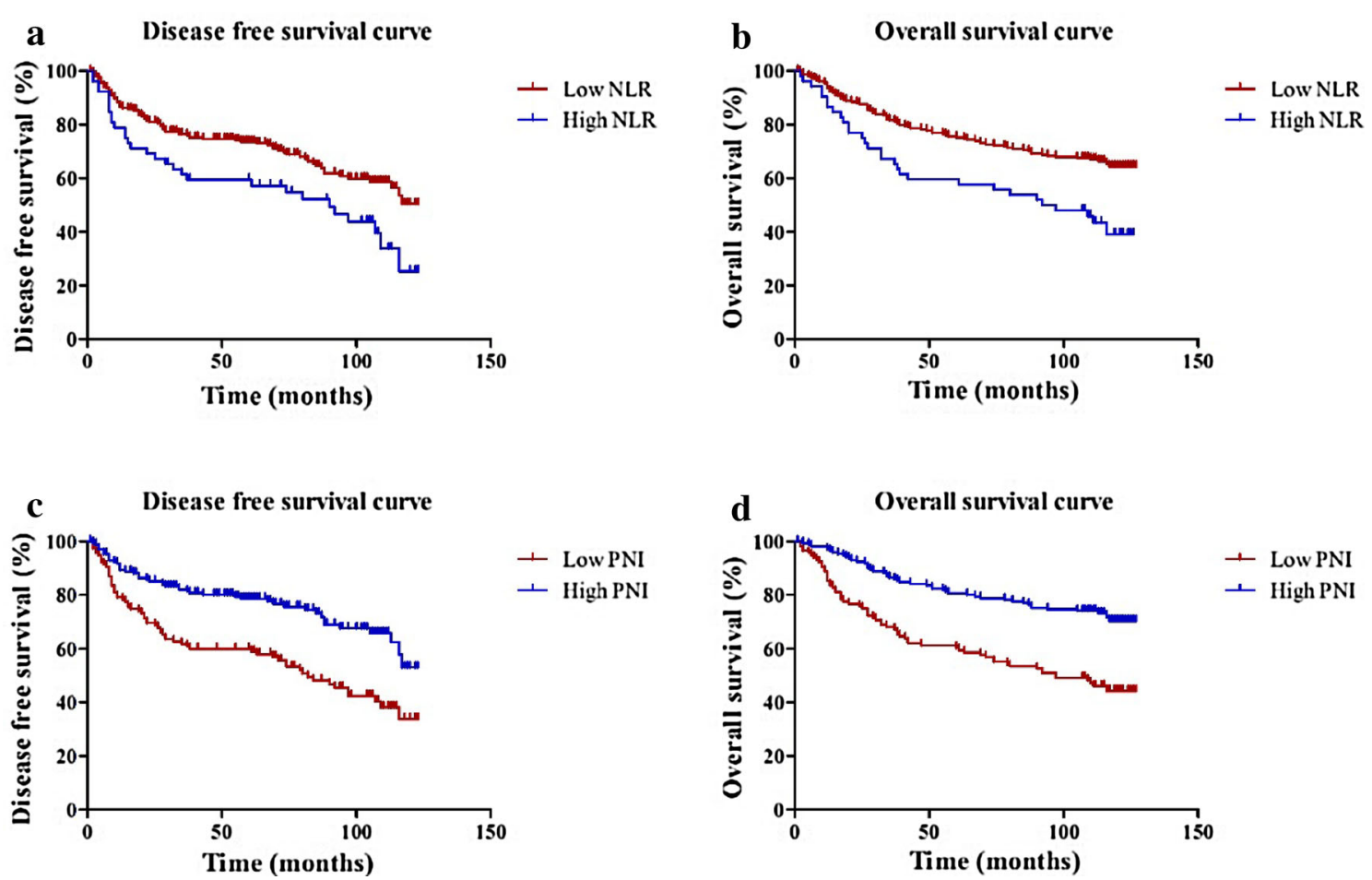

Fig. 2 Disease-free survival and overall survival of patients with gastric cancer stratified by systemic inflammation markers. NLR neutrophillymphocyte ratio, PNI prognostic nutritional index

respectively). However, tumors with high COX-2 expression had a lower mean $\mathrm{CD}^{+}{ }^{+}$immune cell density (553.5/ $\mathrm{mm}^{2}$ vs $\left.452.1 / \mathrm{mm}^{2}, P=0.033\right)$.

\section{Associations between survival outcomes and systemic inflammation markers}

DFS and OS were worse in the high-NLR group than in the low-NLR group (Fig. 2). The 5-year DFS rates were 58.3 and $73.6 \%(P=0.005$, Fig. 2a) and the 5-year OS rates were 58.5 and $75.2 \%$ for the high-NLR group and the lowNLR group respectively ( $P<0.001$, Fig. 2b). Similarly, the PNI also had prognostic value. A low PNI was associated with worse DFS and OS than a high PNI $(P<0.001$ and $P<0.001$ respectively; Fig. 2c, d). The 5-year DFS and OS rates were 59.5 and $59.8 \%$ respectively in the lowPNI group and 78.6 and $80.6 \%$ respectively in the highPNI group. Although there was no significance, patients with $H$. pylori infection had better prognosis than patients without $H$. pylori infection (DFS rate, $85.6 \%$ vs $74.0 \%$, $P=0.069$; OS rate, $86.9 \%$ vs $75.7 \%, P=0.146)$. Similarly, high COX-2 expression was correlated with worse survival tendency than low COX-2 expression (DFS rate, $67.8 \%$ vs $72.8 \%, P=0.170$; OS rate, $68.5 \%$ vs $74.7 \%$, $P=0.100)$.

Because there is a significant correlation between the NLR and PNI $(P<0.001)$, we performed multivariate analysis with Cox's proportional hazards model separately. Each NLR and PNI was included as an independent prognostic factor in the multivariate model for OS (hazard ratio $1.6, P=0.028$, and hazard ratio $1.8, P=0.002$ respectively, Table 4$)$, but the prognostic value did not remain in the multivariate model for DFS $(P=0.325$ and $P=0.069$ respectively).

\section{Discussion}

We found that the NLR and PNI, markers of systemic inflammation, had prognostic value in gastric cancer. These markers were associated with changes in the densities of immune cells in the tumor microenvironment, particularly $\mathrm{CD} 4{ }^{+}$immune cells. These results could explain the poor prognosis associated with systemic inflammation in cancer patients. Furthermore, the results from this study suggest that noninvasive peripheral blood analysis of these markers could be used to assess the tumor microenvironment. This information could be highly valuable for selection of patients who will most likely benefit from cancer immunotherapy.

Markers of systemic of inflammation, including the NLR and PNI, have been shown to have prognostic value for many tumor types [15-22]. Similarly to previous studies, in the present study, both markers were 
Table 4 Multivariate analysis of independent risk factors for recurrence and death of patients with gastric cancer

\begin{tabular}{|c|c|c|c|c|}
\hline \multirow[t]{2}{*}{ Variables } & \multicolumn{2}{|c|}{ Disease-free survival } & \multicolumn{2}{|l|}{ Overall survival } \\
\hline & Hazard ratio $^{a}$ & $P$ & Hazard ratio $^{\mathrm{a}}$ & $P$ \\
\hline \multicolumn{5}{|c|}{ Multivariate analysis with the NLR } \\
\hline Age (years) & & $<0.001$ & & $<0.001$ \\
\hline$<70$ & 1 & & 1 & \\
\hline$\geq 70$ & $2.2(1.5-3.4)$ & & $2.7(1.8-4.0)$ & \\
\hline Lymphatic invasion & & 0.258 & & 0.573 \\
\hline Absent & 1 & & 1 & \\
\hline Present & $1.3(0.8-2.2)$ & & $1.2(0.7-1.9)$ & \\
\hline Vascular invasion & & 0.260 & & 0.073 \\
\hline Absent & 1 & & 1 & \\
\hline Present & $1.3(0.8-2.2)$ & & $1.6(1.0-2.6)$ & \\
\hline Neural invasion & & 0.115 & & 0.096 \\
\hline Absent & 1 & & 1 & \\
\hline Present & $1.5(0.9-2.5)$ & & $1.5(0.9-2.5)$ & \\
\hline \multicolumn{5}{|l|}{ Stage by AJCC7 } \\
\hline I & 1 & $<0.001$ & 1 & $<0.001$ \\
\hline II & $1.8(0.9-3.7)$ & & $1.9(0.9-3.9)$ & \\
\hline III & $4.4(2.2-8.9)$ & & $4.0(2.0-8.0)$ & \\
\hline IV & $10.0(4.2-23.6)$ & & $12.0(4.9-29.0)$ & \\
\hline NLR & & 0.325 & & 0.028 \\
\hline Low & 1 & & 1 & \\
\hline High & $1.2(0.8-1.9)$ & & $1.6(1.1-2.5)$ & \\
\hline \multicolumn{5}{|c|}{ Multivariate analysis with the PNI } \\
\hline Age (years) & & $<0.001$ & & $<0.001$ \\
\hline$<70$ & 1 & & 1 & \\
\hline$\geq 70$ & $2.2(1.4-3.3)$ & & $2.6(1.7-3.9)$ & \\
\hline Lymphatic invasion & & 0.301 & & 0.753 \\
\hline Absent & 1 & & 1 & \\
\hline Present & $1.3(0.8-2.2)$ & & $1.1(0.7-1.8)$ & \\
\hline Vascular invasion & & 0.411 & & 0.134 \\
\hline Absent & 1 & & 1 & \\
\hline Present & $1.2(0.7-2.1)$ & & $1.5(0.9-2.4)$ & \\
\hline Neural invasion & & 0.096 & & 0.070 \\
\hline Absent & 1 & & 1 & \\
\hline Present & $1.5(0.9-2.5)$ & & $1.6(1.0-2.6)$ & \\
\hline Stage by AJCC7 & & $<0.001$ & & $<0.001$ \\
\hline I & 1 & & 1 & \\
\hline II & $1.9(0.9-3.8)$ & & $2.0(1.0-4.0)$ & \\
\hline III & $4.5(2.3-8.9)$ & & $4.2(2.2-8.2)$ & \\
\hline IV & $9.5(4.1-22.1)$ & & $11.4(4.8-27.1)$ & \\
\hline PNI & & 0.069 & & 0.002 \\
\hline High & 1 & & 1 & \\
\hline Low & $1.4(1.0-2.1)$ & & $1.8(1.2-2.7)$ & \\
\hline
\end{tabular}

AJCC7 seventh edition of the AJCC Cancer Staging Manual of the American Joint Committee on Cancer, NLR neutrophil-lymphocyte ratio, $P N I$ prognostic nutritional index

${ }^{a}$ The $95 \%$ confidence interval is given in parentheses

capable of predicting prognosis. Poorer prognosis was observed in the high-NLR group and the low-PNI group. In particular, the NLR and PNI were found to be independent prognostic markers even in multivariate analysis for OS.

The association between systemic inflammation and poor prognosis could be explained by the effects on the tumor microenvironment, such as accumulation of cytokines and immune cells that promote tumor progression [16]. However, little mechanistic evidence linking the poor prognosis of cancer patients with systemic inflammation exists, as no previous studies mainly focused on the relationship between the tumor microenvironment and systemic inflammation. Our study evaluated the association between systemic inflammation and tumor-infiltrating immune cells in the tumor microenvironment. Specifically, the density of $\mathrm{CD}^{+}$immune cells was decreased in highNLR and low-PNI patients, who had a worse prognosis. This finding could be ascribed to the function of $\mathrm{CD} 4^{+}$ immune cells, which recognize tumor antigens and activate $\mathrm{CD}^{+} \mathrm{T}$ cells, resulting in cytotoxic effects on tumor cells $[29,30]$. In previous studies, decreased density of $\mathrm{CD}^{+}$ immune cells in the tumor microenvironment has been associated with a poorer prognosis [9, 31]. Notably, we identified an identical relationship associated with the tumor microenvironment in two markers of systemic inflammation, the NLR and PNI.

A higher NLR and a lower PNI were associated with advanced-stage cancer in the present study. This finding provides indirect evidence supporting a role for systemic inflammation in tumor progression. Markers of systemic inflammation were also correlated with clinicopathologic findings, including lymphatic invasion, vascular invasion, and perineural invasion. These associations suggest that systemic inflammation may be linked to the invasive characteristics of the tumor itself. Moreover, we also found an association between systemic inflammation and the presence of specific immune cells in the tumor microenvironment. Thus, systemic inflammation could have affected both the tumor and the tumor microenvironment; however, the interactions that govern the relationship between the tumor and its microenvironment are not yet fully understood. Additionally, H. pylori infection was correlated with the NLR but not the immune cell density in the tumor microenvironment. COX-2 expression was not correlated with the NLR and PNI. However, low COX-2 expression was correlated with higher $\mathrm{CD}^{+}{ }^{+}$immune cell density in the tumor microenvironment in this study. Although there was no significance, $H$. pylori infection and low COX-2 expression was associated with better survival. These results are similar to those of previous studies $[32,33]$. H. pylori infection could be considered as a local factor of the host influencing the tumor microenvironment. COX-2 expression could be considered as a tumor factor. The NLR and PNI are probably systemic factors of the host. Among these factors, there was a slightly different 
association. These results indicate that there are complicated interactions among the tumor, its microenvironment, and systemic inflammation. Therefore, further studies are warranted to identify the main controller of the tumor microenvironment.

Cancer immunotherapies that inhibit negative immune feedback, such as those targeting programmed cell death $1 /$ programmed cell death-ligand 1 and cytotoxic T-lymphocyte-associated protein 4 , have proven efficacious against several tumor types [34-37]. However, not all patients benefit from these cancer immunotherapies, and efficacy differs depending on whether or not the tumor microenvironment is inflamed [13, 14]. To date, no definitive biomarker exists to easily predict the outcomes of these immunotherapies [38, 39]. A defective mismatch repair system was suggested as a candidate to predict the immune system activity [39]. On the basis of our identification of an association between markers of systemic inflammation and the densities of immune cells in the tumor microenvironment in the present study, we propose that the NLR and PNI could be used to ascertain the immunologic status of the tumor microenvironment. Importantly, the NLR and PNI can be easily calculated from peripheral blood counts, eliminating the need for invasive procedures, such as tissue biopsies, to evaluate the tumor microenvironment. Markers of systemic inflammation in the peripheral blood could serve as useful tools for evaluation of the immunoreactivity in the tumor microenvironment, replacing invasive procedures and complex processes. Evaluation of the predictive value of these markers for cancer immunotherapy is clearly warranted.

Nevertheless, the present study has a few limitations. First, it is possible that patients with active systemic inflammation not related to cancer, such as infection, bleeding, and autoimmune diseases, were included because of the retrospective nature of the present study. As our goal was to evaluate cancer-promoting systemic inflammation using specific markers, patients with known active infections were excluded. Second, we did not analyze the specific subtypes of $\mathrm{CD} 4^{+}$immune cells, which have been shown to play different roles in cancer immunology. Furthermore, the role and prognosis of immune cell infiltration may be different according to the infiltration location, such as the invasion margin or stroma. Therefore, additional studies addressing the roles of specific subtypes of $\mathrm{CD}^{+}$ lymphocytes and the infiltration location are needed. Third, we found that, although the NLR and PNI do not have any overlapping parameters, the density of $\mathrm{CD} 4^{+}$immune cells was associated with both the NLR and the PNI in the tumor microenvironment. The underlying reason explaining why systemic inflammation was associated with $\mathrm{CD} 4^{+}$immune cell density but not $\mathrm{CD}^{+}$and $\mathrm{CD} 8^{+}$immune cell density was not evaluated and requires investigation.
In summary, our results demonstrate that the NLR and PNI, markers of systemic inflammation, were associated with immune cell densities in the tumor microenvironment, specifically those of $\mathrm{CD}^{+}{ }^{+}$immune cells. The NLR and PNI also have prognostic value in resected gastric cancer. This study suggests the possibility that the presence of cancer-promoting inflammation in the tumor microenvironment could be assessed noninvasively with markers of systemic inflammation in peripheral blood samples.

Acknowledgments The authors declare that they have no conflict of interest. The study design was approved by the appropriate ethics review boards. The need for informed consent was waived because of the retrospective nature of the study.

\section{References}

1. Hanahan D, Weinberg RA. Hallmarks of cancer: the next generation. Cell. 2011;144:646-74.

2. Bremnes RM, Al-Shibli K, Donnem T, Sirera R, Al-Saad S, Andersen S, et al. The role of tumor-infiltrating immune cells and chronic inflammation at the tumor site on cancer development, progression, and prognosis: emphasis on non-small cell lung cancer. J Thorac Oncol. 2011;6:824-33.

3. Garcia-Martinez E, Gil GL, Benito AC, Gonzalez-Billalabeitia E, Conesa MA, Garcia Garcia T, et al. Tumor-infiltrating immune cell profiles and their change after neoadjuvant chemotherapy predict response and prognosis of breast cancer. Breast Cancer Res. 2014;16:488.

4. Cai T, Nesi G, Boddi V, Mazzoli S. Dal Canto M, Bartoletti R. Prognostic role of the tumor-associated tissue inflammatory reaction in transitional bladder cell carcinoma. Oncol Rep. 2006; 16:329-34.

5. Ruffini E, Asioli S, Filosso PL, Lyberis P, Bruna MC, Macri L, et al. Clinical significance of tumor-infiltrating lymphocytes in lung neoplasms. Ann Thorac Surg 2009;87:365-71; discussion $371-2$.

6. Leffers N, Gooden MJ, de Jong RA, Hoogeboom BN, ten Hoor $\mathrm{KA}$, Hollema $\mathrm{H}$, et al. Prognostic significance of tumor-infiltrating T-lymphocytes in primary and metastatic lesions of advanced stage ovarian cancer. Cancer Immunol Immunother. 2009;58:449-59.

7. Tomsova M, Melichar B, Sedlakova I, Steiner I. Prognostic significance of $\mathrm{CD} 3+$ tumor-infiltrating lymphocytes in ovarian carcinoma. Gynecol Oncol. 2008;108:415-20.

8. Dunn GP, Dunn IF, Curry WT. Focus on TILs: prognostic significance of tumor infiltrating lymphocytes in human glioma. Cancer Immunity. 2007;7:12.

9. Kim JW, Nam KH, Ahn SH, Park DJ, Kim HH, Kim SH, et al. Prognostic implications of immunosuppressive protein expression in tumors as well as immune cell infiltration within the tumor microenvironment in gastric cancer. Gastric Cancer. 2016;19:42-52.

10. Salgado R, Denkert C, Campbell C, Savas P, Nucifero P, Aura C, et al. Tumor-infiltrating lymphocytes and associations with pathological complete response and event-free survival in HER2positive early-stage breast cancer treated with lapatinib and trastuzumab: a secondary analysis of the NeoALTTO trial. JAMA Oncol. 2015;1:448-54.

11. Loi S, Michiels S, Salgado R, Sirtaine N, Jose V, Fumagalli D, et al. Tumor infiltrating lymphocytes are prognostic in triple negative breast cancer and predictive for trastuzumab benefit in 
early breast cancer: results from the FinHER trial. Ann Oncol. 2014;25:1544-50.

12. Denkert C, Loibl S, Noske A, Roller M, Muller BM, Komor M, et al. Tumor-associated lymphocytes as an independent predictor of response to neoadjuvant chemotherapy in breast cancer. J Clin Oncol. 2010;28:105-13.

13. Gajewski TF, Fuertes M, Spaapen R, Zheng Y, Kline J. Molecular profiling to identify relevant immune resistance mechanisms in the tumor microenvironment. Curr Opin Immunol. 2011;23:286-92.

14. Gajewski TF, Schreiber H, Fu YX. Innate and adaptive immune cells in the tumor microenvironment. Nat Immunol. 2013;14:1014-22.

15. Lee S, Oh SY, Kim SH, Lee JH, Kim MC, Kim KH, et al. Prognostic significance of neutrophil lymphocyte ratio and platelet lymphocyte ratio in advanced gastric cancer patients treated with FOLFOX chemotherapy. BMC Cancer. 2013;13:350.

16. Templeton AJ, McNamara MG, Šeruga B, Vera-Badillo FE, Aneja P, Ocana A, et al. Prognostic role of neutrophil-to-lymphocyte ratio in solid tumors: a systematic review and metaanalysis. J Natl Cancer Inst. 2014;106:dju124.

17. Proctor MJ, Morrison DS, Talwar D, Balmer SM, Fletcher CD, O'Reilly DS, et al. A comparison of inflammation-based prognostic scores in patients with cancer. A Glasgow inflammation outcome study. Eur J Cancer. 2011;47:2633-41.

18. Pinato DJ, North BV, Sharma R. A novel, externally validated inflammation-based prognostic algorithm in hepatocellular carcinoma: the prognostic nutritional index (PNI). Br J Cancer. 2012;106:1439-45.

19. Fox P, Hudson M, Brown C, Lord S, Gebski V, De Souza P, et al. Markers of systemic inflammation predict survival in patients with advanced renal cell cancer. Br J Cancer. 2013;109:147-53.

20. Stotz M, Gerger A, Eisner F, Szkandera J, Loibner H, Ress AL, et al. Increased neutrophil-lymphocyte ratio is a poor prognostic factor in patients with primary operable and inoperable pancreatic cancer. Br J Cancer. 2013;109:416-21.

21. Kim JH, Han DS, Bang HY, Kim PS, Lee KY. Preoperative neutrophil-to-lymphocyte ratio is a prognostic factor for overall survival in patients with gastric cancer. Ann Surg Treat Res. 2015;89:81-6.

22. Kumar R, Geuna E, Michalarea V, Guardascione M, Naumann U, Lorente D, et al. The neutrophil-lymphocyte ratio and its utilisation for the management of cancer patients in early clinical trials. Br J Cancer. 2015;112:1157-65.

23. Ohsugi Y. Recent advances in immunopathophysiology of interleukin-6: an innovative therapeutic drug, tocilizumab (recombinant humanized anti-human interleukin-6 receptor antibody), unveils the mysterious etiology of immune-mediated inflammatory diseases. Biol Pharm Bull. 2007;30:2001-6.

24. Bruno TC, French JD, Jordan KR, Ramirez O, Sippel TR, Borges $\mathrm{VF}$, et al. Influence of human immune cells on cancer: studies at the University of Colorado. Immunol Res. 2013;55:22-33.
25. Sarraf KM, Belcher E, Raevsky E, Nicholson AG, Goldstraw P, Lim E. Neutrophil/lymphocyte ratio and its association with survival after complete resection in non-small cell lung cancer. J Thorac Cardiovasc Surg. 2009;137:425-8.

26. Nozoe T, Ninomiya M, Maeda T, Matsukuma A, Nakashima $H$, Ezaki T. Prognostic nutritional index: a tool to predict the biological aggressiveness of gastric carcinoma. Surg Today. 2010;40:440-3.

27. Anraku M, Cunningham KS, Yun Z, Tsao MS, Zhang L, Keshavjee $S$, et al. Impact of tumor-infiltrating T cells on survival in patients with malignant pleural mesothelioma. J Thorac Cardiovasc Surg. 2008;135:823-9.

28. Vergani A, D'Addio F, Jurewicz M, Petrelli A, Watanabe T, Liu $\mathrm{K}$, et al. A novel clinically relevant strategy to abrogate autoimmunity and regulate alloimmunity in NOD mice. Diabetes. 2010;59:2253-64.

29. Yu P, Fu YX. Tumor-infiltrating T lymphocytes: friends or foes? Lab Invest. 2006;86:231-45.

30. Pardoll DM, Topalian SL. The role of CD4+ T cell responses in antitumor immunity. Curr Opin Immunol. 1998;10:588-94.

31. Gooden MJ, de Bock GH, Leffers N, Daemen T, Nijman HW. The prognostic influence of tumour-infiltrating lymphocytes in cancer: a systematic review with meta-analysis. $\mathrm{Br} \mathrm{J}$ Cancer. 2011;105:93-103.

32. Chang WJ, Du Y, Zhao X, Ma LY, Cao GW. Inflammationrelated factors predicting prognosis of gastric cancer. World $\mathrm{J}$ Gastroenterol. 2014;20:4586-96.

33. Song J, Su H, Zhou YY, Guo LL. Cyclooxygenase-2 expression is associated with poor overall survival of patients with gastric cancer: a meta-analysis. Dig Dis Sci. 2014;59:436-45.

34. Motzer RJ, Escudier B, McDermott DF, George S, Hammers HJ, Srinivas $\mathrm{S}$, et al. Nivolumab versus everolimus in advanced renalcell carcinoma. N Engl J Med. 2015;373:1803-13.

35. Larkin J, Chiarion-Sileni V, Gonzalez R, Grob JJ, Cowey CL, Lao $\mathrm{CD}$, et al. Combined nivolumab and ipilimumab or monotherapy in untreated melanoma. $\mathrm{N}$ Engl $\mathrm{J}$ Med. 2015;373:23-34.

36. Garon EB, Rizvi NA, Hui R, Leighl N, Balmanoukian AS, Eder JP, et al. Pembrolizumab for the treatment of non-small-cell lung cancer. N Engl J Med. 2015;372:2018-28.

37. Borghaei H, Paz-Ares L, Horn L, Spigel DR, Steins M, Ready $\mathrm{NE}$, et al. Nivolumab versus docetaxel in advanced nonsquamous non-small-cell lung cancer. N Engl J Med. 2015;373:1627-39.

38. Bjoern J, Juul Nitschke N, Zeeberg Iversen T, Schmidt H, Fode K, Svane IM. Immunological correlates of treatment and response in stage IV malignant melanoma patients treated with ipilimumab. Oncoimmunology. 2015;5:e1100788.

39. Giampieri R, Maccaroni E, Mandolesi A, Del Prete M, Andrikou K, Faloppi L, et al. Mismatch repair deficiency may affect clinical outcome through immune response activation in metastatic gastric cancer patients receiving first-line chemotherapy. Gastric Cancer. 2016. doi:10.1007/s10120-016-0594-4. 